\title{
Vegetation structure of plantain-based agrosystems determines numerical dominance in community of ground- dwelling ants
}

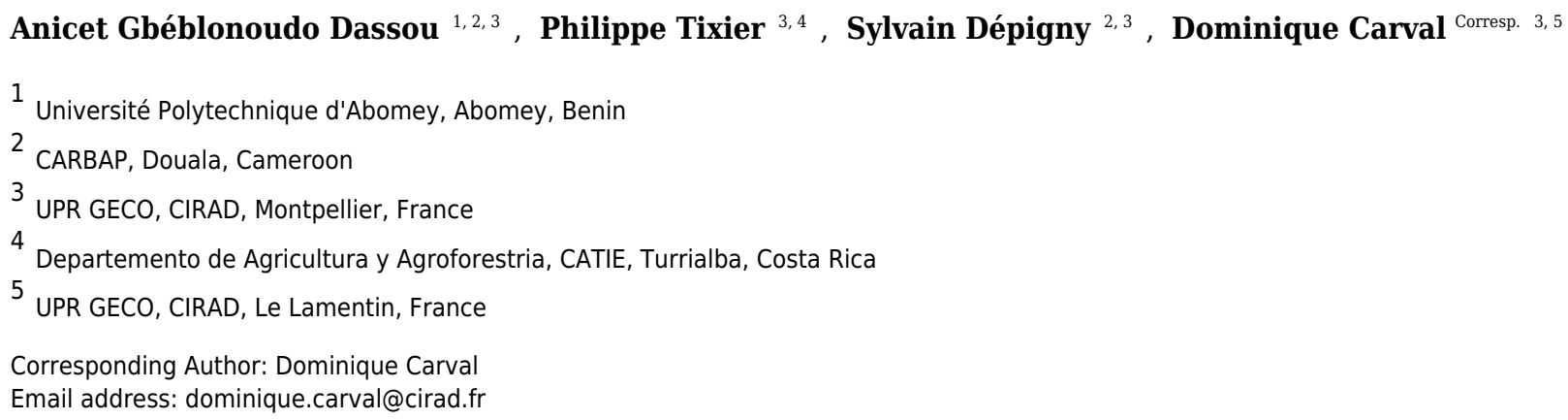

In tropics, ants can represent an important part of animal biomass and are known to be involved in ecosystem services, such as pest regulation. Understanding the mechanisms underlying the structuring of local ant communities is therefore important in agroecology. In the humid tropics of Africa, plantains are cropped in association with many other annual and perennial crops. Such agrosystems differ greatly in vegetation diversity and structure and are well-suited for studying how habitat-related factors affect the ant community. We analysed abundance data for the six numerically dominant ant taxa in 500 subplots located in 20 diversified, plantain-based fields. We found that the density of crops with foliage at intermediate and high canopy strata determined the numerical dominance of species. We found no relationship between the numerical dominance of each ant taxon with the crop diversity. Our results indicate that the manipulation of the densities of crops with leaves in the intermediate and high strata may help maintain the coexistence of ant species by providing different habitat patches. Further research in such agrosystems should be performed to assess if the effect of vegetation structure on ant abundance could result in efficient pest regulation. 
1 Vegetation structure of plantain-based agrosystems determines numerical

2 dominance in community of ground-dwelling ants

3

4

5 Anicet Gbèblonoudo Dassou ${ }^{1,2,3}$, Philippe Tixier ${ }^{1,4}$, Sylvain Depigny ${ }^{1,2}$, Dominique Carval ${ }^{1,5^{*}}$

6 CIRAD, UPR GECO, F-34398, Montpellier, France

$7 \quad{ }^{2}$ CARBAP, BP 832, Douala, Cameroon

8 3Université Polytechnique d'Abomey, BP 2282, Abomey, Benin

$9 \quad{ }^{4}$ Departamento de Agricultura y Agroforesteria, CATIE, CR-30501, Turrialba, Costa Rica

$10 \quad{ }^{5}$ CIRAD, UPR GECO, F-97285 Le Lamentin, Martinique, France

11

12 *Correspondence:

13 Dominique Carval

14 Persyst - UPR GECO

15 Bâtiment PS4 - Bureau 002

16 TA B-26 / PS4 - Boulevard de la Lironde

1734398 Montpellier Cedex 5 France

18 dominique.carval@cirad.fr

19 Tél : +33467616544

20

21

22 


\section{Abstract}

24 In tropics, ants can represent an important part of animal biomass and are known to be involved

25 in ecosystem services, such as pest regulation. Understanding the mechanisms underlying the

26 structuring of local ant communities is therefore important in agroecology. In the humid tropics

27 of Africa, plantains are cropped in association with many other annual and perennial crops. Such

28 agrosystems differ greatly in vegetation diversity and structure and are well-suited for studying

29 how habitat-related factors affect the ant community. We analysed abundance data for the six

30 numerically dominant ant taxa in 500 subplots located in 20 diversified, plantain-based fields.

31 We found that the density of crops with foliage at intermediate and high canopy strata

32 determined the numerical dominance of species. We found no relationship between the

33 numerical dominance of each ant taxon with the crop diversity. Our results indicate that the

34 manipulation of the densities of crops with leaves in the intermediate and high strata may help

35 maintain the coexistence of ant species by providing different habitat patches. Further research in

36 such agrosystems should be performed to assess if the effect of vegetation structure on ant

37 abundance could result in efficient pest regulation. 
40

41

42

43

44

\section{Introduction}

In tropics, ants are known to potentially represent the major part of animal biomass (Hölldobler and Wilson, 1990). Moreover, in agrosystems, they are known to be involved in pest regulation and other ecosystem services (Perfecto and Vandermeer, 2006, Philpott and Armbrecht, 2006). Understanding the factors affecting the structure of local ant communities is therefore an important issue in agroecology. The structure of the community may be related to physical factors that affect physiology of organisms (humidity and temperature) and ecological factors (Philpott and Armbrecht, 2006). Ecological factors, which are the focus of the present study, can include both ecological interactions (e.g. foraging interference) and habitat-related factors (e.g. nesting sites)..

Previous studies have shown that vegetation may affect the ant communities by affecting habitat structure (Perfecto and Vandermeer, 1996, Vasconcelos et al., 2008, House et al., 2012, Murnen et al., 2013). A common observation of these studies is that habitats that reduce the abundance of a dominant ant species increase ant species richness. Perfecto and Vandermeer (1996) showed that the addition of artificial shade to a tropical agrosystem decreased the abundance of the dominant ant Solenopsis geminata while it increased the abundance of other ant species. Vasconcelos et al. (2008) found that trees and tall grasses affect ant species composition in savannas of South America; more specifically, they reported that tall grass cover reduced the incidence of the dominant ant species, Solenopsis substituta. In a study of ants in an agricultural matrix, House et al. (2012) found that species richness and abundance were higher in native woodlands than in pastures or crops but dominance of Dolichoderinae ants was higher in pastures or crops than in native woodlands. By manipulating food and nesting site availability, Murnen et al. (2013) demonstrated that ant community composition is greatly influenced by 
63 habitat type, which determines nesting resource availability, while food quantity alone had no

64 effect on community composition.

65 Ant diet varies within and between subfamilies and genera. Many ants may be mainly 66 omnivorous and opportunistic, while others are specialized for predation, fungus-growing, or 67 herbivory (seeds and nectar) (Hölldobler and Wilson, 1990). Therefore, at the community level, 68 ant diets represent a continuum between herbivory and strict predation (Bluthgen et al., 2003) 69 and are likely to be affected by plant diversity. Bluthgen et al. (2003) proved through isotope analysis that the dominant ant species with small to intermediate colonies in tree canopies tend to

71 be herbivorous (including feeding on extrafloral and floral nectaries), that the dominant canopy

72 ants with large colonies tend to be omnivorous, and that understorey or ground-dwelling ants

73 tend to occupy higher trophic levels.

74 In the humid tropics of Africa, plantains (Musa AAB genome) are cropped in association with 75 annual crops (root, tuber, and vegetable crops) and perennial crops (cocoa, coffee, and palm)

76 (Côte et al., 2010). Because such agrosystems differ greatly in vegetation diversity and structure,

77 they are useful for studying how habitat-related factors affect ant community structure. Using diversified plantain agrosystems in the current study, we (i) determined the dominant and

79 subordinate ant species in the dry and rainy seasons and (ii) tested the hypotheses that local 80 vegetation structure and plant diversity determine the numerically dominant ant at the genus 81 level. 
84

85

86

87

88

89

90

91

92

93

94

95

96

97

98

99

100

101

102

103

\section{Methods}

Fields, plots, and subplots

8

We conducted our study in the Moungo department of the Littoral Region of Cameroon (Central Africa) from June 2012 to February 2013. We selected 20 farmer fields near the CARBAP research station (4 $34^{\prime} 11.33^{\prime \prime} \mathrm{N} ; 9^{\circ} 38^{\prime} 48.96^{\prime}, \mathrm{E} ; 79 \mathrm{~m}$ a.s.1.). Field experiments were approved by the CARBAP Research Station (Njombé, Cameroon) where the experiment was performed. All the fields have a young, brown soil derived from a volcanic platform (Delvaux et al., 1989). The climate is humid tropical with a monthly mean temperature ranging from 25.0 to $27.4^{\circ} \mathrm{C}$ and a mean annual rainfall of $2610 \mathrm{~mm}$. All fields contained plantain crops (Musa $A A B$ genome) and a diverse array of other annual and perennial crops. Pesticides and fertilizers are rarely applied in these low input agrosystems.

In each field, we assessed ants and crops in one 12 X $12 \mathrm{~m}$ plot, which was subdivided into 25 subplots of 2.4 X $2.4 \mathrm{~m}$. We sampled during two periods: the rainy season (mid-March 2012 to mid-November 2012) and the dry season (mid-November 2012 to February 2013).

\section{Vegetation structure and diversity}

For all subplots, we identified all cropped plants, measured their density (number of

plants of each species per $\mathrm{m}^{2}$ ), and recorded their coordinates with a measuring tape (using subplot corners as a references to minimize error). We classified the plant species into four categories according to the location of their canopies relative to the soil surface: low stratum 
104 (height $\leq 2 \mathrm{~m})$, intermediate stratum $(2 \mathrm{~m}<$ height $\leq 6 \mathrm{~m})$, high stratum (height $>6 \mathrm{~m})$, and Musa

105 group. For each category, we calculated the density of plants, i.e. the number of plants of a 106 considered category per $\mathrm{m}^{2}$. Plant diversity at each subplot was assessed by the Shannon Index 107 (Shannon, 1948), which was calculated with the 'diversity' function of the 'VEGAN' R package 108 (Dixon, 2003).

\section{Bait sampling}

In each subplot, we measured ant abundance by using $2 / 3$ tuna- $1 / 3$ honey baits. The 2 cm-radius bait was placed in the centre of a white ceramic square tile (30 $\mathrm{cm}$ side), which was itself placed at the ground level in the centre of the subplot. Thirty minutes after the baits were deployed, we counted the individuals of different species/morphospecies present on the tile. Samples of all observed species were collected and conserved in $70 \%$ alcohol to perform identification to genus according to Fisher and Bolton (2016), then to species. When we were not able to determine the species, a morphospecies number was assigned to the individual on the basis of morphological specificities. The ants were also recorded according to a 6 point abundance scale (following Andersen, 1997; Parr et al, 2005; Baccaro et al, 2010). We

120 performed bait samples twice for each subplot, during two periods: the rainy season (mid-March 1212012 to mid-November 2012) and the dry season (mid-November 2012 to February 2013). 

numerical and behavioral criteria of dominance to determine dominant, subdominant and subordinate ants. The dominant (respectively subdominant) ants were considered as those that were recorded in $>10 \%$ of all baits, controlled $>25 \%$ (respectively $>10 \%$ ) of baits where they occurred, and with a mean abundance score (i.e. the sum of the abundance scores for the species at all baits divided by the number of baits at which the species was present) of $>3.5$ (respectively $>3$ ). All other species that did not meet all these criteria was considered as subordinate species. Then, we grouped ants by genus and we excluded Odontomachus troglodytes from the following analysis because of its very low occurrence on baits (see Table 1). We assessed the influence of the season (dry, rainy) on the occurrence of each genus by using binomial generalized linear models.

\section{Effect of vegetation strata on numerical dominance of ants}

For each subplot, we attributed rank values for each ant genus according to their respective abundances (Parr and Gibb, 2010). The genera with the rank of one were considered as the numerically dominant genus at the subplot scale. Then, we used multinomial logit model to assess the effect of plant diversity and of the density of each stratum on the probability that an ant genus was numerically dominant. We used likelihood ratio tests (LRTs) to select the best model by removing non-significant parameters in a backwards-stepwise process. The selection 143 procedure was continued until a model was found in which all effects were significant (Zuur et 144 al., 2009). Multinomial models were estimated using the 'VGAM' package (Yee, 2010). 
All statistical analyses were performed with R 3.3.1 (R Development Core Team, 2016) 146 and with an alpha level of 0.05.

147

148

\section{Results}

150 Overall, we recorded 20910 ants belonging to 11 species or morphospecies. Pheidole spp. was

151 the most abundant taxon (9200 individuals) followed by Paratrechina longicornis (3037 152 individuals), Monomorium sp. 1 (1696 individuals), Tetramorium sp. (1562 individuals), 153 Camponotus acvapimensis (1517 individuals), Camponotus brutus (1328 individuals), 154 Monomorium bicolor (1296 individuals) and Axinidris murielae (895 individuals). The 155 remaining four species were relatively scarce, namely: Camponotus sp. 1 (166 individuals), 156 Odontomachus troglodytes (144 individuals), Monomorium sp. 2 (35 individuals) and 157 Camponotus sp. 2 (34 individuals). occurrence on baits, a large proportion of controlled baits and a high mean score abundance 162 (Table 1). Axinidris murielae was identified as a subdominant species because it combined a 163 moderate proportion of controlled baits and a high mean score abundance (Table 1).. All other 164 species were considered subordinate (Table 1). 
Occurence of each genus was not significantly affected by the season, except for 166 Axinidris murielae which was absent on baits in the rainy season and for Pheidole spp. whose 167 occurrence was higher in the rainy season (Fig. S1 \& S2, Table S1). Frequency of numerical 168 dominance was similar in the rainy season and dry season (Fig. 1).

\section{Effect of vegetation strata on numerical dominance of ants}

171 We recorded 31 plant species, which we grouped into four vegetation strata (Table 2). The

172 probability of dominance of each ant taxa was not significantly affected by the density of plants

173 in the low and Musa strata but was significantly affected by the density of plants in the

174 intermediate and high strata (Table 3). The dominance of Pheidole spp., Monomorium spp., and 175 Tetramorium sp. was negatively correlated with the density of plants in the intermediate and high 176 strata, whereas the dominance of $P$. longicornis, Camponotus spp., and A. murielae was 177 positively correlated with the density of plants in the intermediate and high strata (Fig. 2). The 178 probability of dominance of each ant taxa was not significantly correlated with plant diversity 179 (Table 2).

\section{Discussion}

We found that ants of the Pheidole genus were the numerically dominant ants in our study fields. Abera-Kalibata et al. (2007) found that three morphospecies of Pheidole were 
185 among the most abundant ants in banana fields in Uganda. Elsewhere, we observed similar

186 frequencies of numerical dominance for P. longicornis, Camponotus spp., and Monomorium spp.

187 These results also agree with the literature in that ants of the Camponotus genus are considered

188 ubiquitous subordinate ants that may numerically dominate arboreal vegetation (Davidson, 1997,

189 Tadu et al., 2014). The tramp crazy ant P. longicornis is an exploitative competitor and uses a

190 foraging strategy with worker recruitment occurring at a short-range of distance (Kenne et al.,

191 2005). The numerical dominance of $P$. longicornis on baits is thought to be principally linked to

192 its foraging speed (Kenne et al., 2005). Tetramorium sp. and A. murielae were numerically

193 dominant less frequently than the other taxa. However, when present on baits, A. murielae

194 displayed a high abundance score resulting in the control of a moderate proportion of baits.

We hypothesized that the vegetation structure determines which species numerically dominates the ground-dwelling ant community at the local (subplot) scale. We indeed found that the general trend of numerical dominance can be altered by the density of plants in the intermediate and high strata. The probability of being numerically dominant for ground-dwelling ants like Pheidole spp., Monomorium spp., and Tetramorium sp. decreased as the density of the intermediate and high strata increased, while the probability of being dominant for the mostly arboreal taxon Camponotus spp. and the tramp species $P$. longicornis increased with the density of plants in the intermediate stratum. A high density of high strata plants also increased the abundance of these taxa, but as the density of plants with leaves in the high stratum increased, the dominance of the strictly arboreal ant $A$. murielae increased. We found no effect of plant density in low stratum on the dominance of ants. In Australia, Stevens et al. (2007) also found no effect of ground cover on the dominance of the Dolichoderinae ant Iridomyrmex in citrus groves.

207 Together, these results suggest that plant density in the low stratum does not directly modify 
208 habitats for the six studied taxa (Andersen, 1995). However, the low stratum may have 209 influenced the cryptic ants (e.g., hypogaeic and litter-dwelling ants), as demonstrated by 210 Bestelmeyer and Wiens (1996); that possibility should be investigated in future research. communities through three processes: (i) resources increase with woody plant density, and an increase in resources would enhance ant species diversity; (ii) habitat conditions are altered by the density of woody plants, and habitat conditions would affect which ants are numerically dominant; and (iii) the variation in woody plant densities may lead to species-area patterns. Our results on dominance hierarchies are in agreement with the second and third processes. Indeed, 217 the effects of strata densities are consistent with the preferred ecological niches of the six studied ant taxa. For instance, ground-dwelling taxa were, in our study, negatively related to the density 219 of arboreal habitats (e.g., intermediate and high strata). This agrees with Lassau and Hochuli (2004) who found that the abundance of species that only nest on ground was negatively related to the density of tree cover. The abundance of Camponotus spp., which may forage both on the 222 ground and in the arboreal stratum, was positively related to the density of high strata plants, which correspond to arboreal nesting or foraging habitats, except in the extreme densities of the high stratum, which coincided with the numerical dominance of $A$. murielae The members of the latter species nest strictly in trees and are primarily arboreal foragers but may occasionally forage in ground litter (Snelling, 2007). We observed individuals of A. murielae on baits only in the dry season, which is consistent with the view that arboreal ant species forage at ground-level during

228 the dry season, when resources in trees are relatively scarce (Delabie et al., 2000). P. longicornis, known as the crazy ant, is a native of West Africa and prefers moist habitats for reproduction (Kenne et al., 2005). The nests of this tramp species are often small and ephemeral and occur in a 
231 wide range of habitats (e.g., plant cavities, live or dead plants, leaf litter). An increase in the

232 density of plants with leaves in the intermediate and high strata may enhance the local

233 hygrometry and therefore increase the nesting sites available for $P$. longicornis. However, $P$.

234 longicornis is a weak competitor against common ground-dwelling ant species (including

235 Camponotus spp.) in its native range (Kenne et al., 2005). We hypothesize that, as the density of

236 plants with leaves in the high stratum increases in a plantain field, the availability of foraging

237 and nesting sites increases, and better competitors like Camponotus spp. and Axinidris murielae

238 predominate the area and resulting in a decrease in the positive effect of the intermediate stratum

239 density on P. longicornis.

We found no relationship between the numerical dominance of each ant taxon with the

crop diversity. One explanation may be that the studied taxon were omnivores that feed in

242 multiple trophic level (consumers of plant resources, hemipteran honeydew, herbivores,

243 predatory arthropods or even scavengers), and may not be affected by the identity of plants that

244 support only a part of their diet. One other explanation may be that the presence and abundance

245 of species is linked to nesting habits. For instance, most Camponotus spp. forage both arboreally

246 and on the ground but have specialized nesting habits in that they generally start colonies in

247 living or dead trunks, such as banana pseudostems. Davidson (1997) argued that this kind of ant

248 species locates its nest on preferred resource plants. Consequently, plant diversity would not

249 modify their nesting or foraging habits.

Ants have been increasingly recognized as important predators in tropical and subtropical agricultural systems (Way and Khoo, 1992, Perfecto and Castineiras, 1998, Offenberg, 2015).

252 Ants have complex and often strong effects on lower trophic levels (Philpott et al., 2008) and 
254 banana weevil Cosmopolites sordidus (Germar) (Coleoptera: Curculionidae) is the most

255 important pest (Gold et al., 2001). In Martinique, using metabarcoding analysis and predation

256 tests, Mollot et al. (2014) recently showed that C. sordidus is preyed on by the arboreal ant

257 Camponotus sexguttatus F. (Hymenoptera: Formicidae) and the ground-dwelling ant Solenopisis

258 geminata. In the current study, we have shown that Camponotus spp. were favoured by the

259 intermediate and high strata. Pheidole spp. has been suggested to be a potential natural enemy of

260 C. sordidus in Uganda (Abera-Kalibata et al., 2007, Abera-Kalibata et al., 2008), and Pheidole

261 megacephala and Tetramorium guineense (Bernard) (Hymenoptera: Formicidae) are used as

262 biological control agents of C. sordidus in Cuba (Castineiras and Ponce, 1991, Perfecto and

263 Castineiras, 1998). Our results indicate that the manipulation of the densities of crops with leaves

264 in the intermediate and high strata may help maintain the coexistence of ant species by providing

265 different habitat patches. Further research in such agrosystems should be performed to assess if

266 the effect of vegetation structure on ant abundance could result in efficient pest regulation.

\section{Acknowledgments}

268 We thank B. Jaffee for revising English language of the manuscript. 
271 References

272 Abera-Kalibata, A. M., Gold, C. S. \& Van Driesche, R. 2008. Experimental evaluation of the 273 impacts of two ant species on banana weevil in Uganda. Biological Control, 46, 147-157.

274 Abera-Kalibata, A. M., Gold, C. S., Van Driesche, R. G. \& Ragama, P. E. 2007. Composition, 275 distribution, and relative abundance of ants in banana farming systems in Uganda. Biological Control, 40, 168-178.

277

278

279

280

281

282

283

284

285

286

287

288

289

290

291

Andersen, A. N. 1995. A classification of australian ant communities, based on functionalgroups which parallel plant life-forms in relation to stress and disturbance. Journal of Biogeography, 22, 15-29.

Andersen, A. N. 1997. Functional groups and patterns of organization in North American ant communities: a comparison with Australia. Journal of Biogeography, 24, 433-460.

Baccaro, F. B., Ketelhut, S. M. \& De Morais, J. W. 2010. Resource distribution and soil moisture content can regulate bait control in an ant assemblage in Central Amazonian forest. Austral Ecology, 35, 274-281.

Bestelmeyer, B. T. \& Wiens, J. A. 1996. The effects of land use on the structure of groundforaging ant communities in the Argentine Chaco. Ecological Applications, 6, 12251240.

Bluthgen, N., Gebauer, G. \& Fiedler, K. 2003. Disentangling a rainforest food web using stable isotopes: dietary diversity in a species-rich ant community. Oecologia, 137, 426-435.

Carval, D., Cotté, V., Resmond, R., Perrin, B. \& Tixier, P. 2016. Dominance in a ground dwelling ant community of banana agroecosystem. Ecology and Evolution, 6, 8617-8631. 
292 Castineiras, A. \& Ponce, E. 1991. Effectiveness of the use of Pheidole megacephala 293 (Hymenoptera: Formicidae) in the biological control of Cosmopolites sordidus (Coleoptera: Curculionidae). Proteccion de Plantas. Cuba.

295 Côte, F., Tomekpe, K., Staver, C., Dépigny, S., Lescot, T. \& Markham, R. 2010. Agro296 ecological intensification in banana and plantain (musa spp.): An approach to develop more sustainable cropping systems for both smallholder farmers and large-scale

Davidson, D. W. 1997. The role of resource imbalances in the evolutionary ecology of tropical 300 arboreal ants. Biological Journal of the Linnean Society, 61, 153-181.

Delabie, J. H. C., Agosti, D. \& Do Nascimento, I. C. 2000. Litter ant communities of the Brazilian Atlantic rain forest region. Curtin University of Technology School of Environmental Biology Bulletin, 18, 1-17.

Delvaux, B., Herbillon, A. J. \& Vielvoye, L. 1989. Characterization of a weathering sequence of soils derived from volcanic ash in cameroon - taxonomic, mineralogical and agronomic implications. Geoderma, 45, 375-388.

Dixon, P. 2003. VEGAN, a package of $\mathrm{R}$ functions for community ecology. Journal of Vegetation Science, 14, 927-930.

Fisher B.L. and Bolton, B. 2016. Ants of Africa and Madagascar: A guide to the genera.

Gold, C. S., Pena, E. J. \& Ekaramura, E. B. 2001. Biology and integrated pest management for University of California Press, $512 \mathrm{pp}$. the banana weevil Cosmopolites sordidus (Germar) (Coleoptera: Curculionidae). Integrated Pest Management Reviews, 6, 79-155.

314 Hölldobler, B. \& Wilson, E. O. 1990. The Ants., Berlin, Heidelberg, New York, Belknap Press. 
315 House, A. N., Burwell, C., Brown, S. \& Walters , B. 2012. Agricultural matrix provides modest

316

317

318

319

320

321

322

323

324

325

326

327

328

329

330

331

332

333

334

335

336

337 habitat value for ants on mixed farms in eastern Australia. Journal of Insect Conservation, 16, 1-12.

Kenne, M., Mony, R., Tindo, M., Njaleu, L. C. K., Orivel, J. \& Dejean, A. 2005. The predatory behaviour of a tramp ant species in its native range. Comptes Rendus Biologies, 328, 1025-1030.

Lassau, S. A. \& Hochuli, D. F. 2004. Effects of habitat complexity on ant assemblages. Ecography, 27, 157-164.

Mollot, G., Duyck, P.-F., Lefeuvre, P., Lescourret, F., Martin, J.-F., Piry, S., Canard, E. \& Tixier, P. 2014. Cover cropping alters the diet of arthropods in a banana plantation: A metabarcoding approach. Plos One, 9.

Murnen, C. J., Gonthier, D. J. \& Philpott, S. M. 2013. Food webs in the litter: Effects of food and nest addition on ant communities in coffee agroecosystems and forest. Environmental Entomology, 42, 668-676.

Offenberg, J. 2015. REVIEW: Ants as tools in sustainable agriculture. Journal of Applied Ecology, 52, 1197-1205.

Parr, C. L. \& Gibb, H. 2010. Competition and the role of dominant ants. In: Lach, L., Parr, C. L. \& Abbott, K. (eds.) Ant ecology. Oxford: Oxford University Press.

Parr, C. L., Sinclair, B. J., Andersen, A. N., Gaston, K. J. \& Chown, S. L. 2005. Constraint and competition in assemblages: A cross-continental and modeling approach for ants. American Naturalist, 165, 481-494.

Perfecto, I. 1991. Ants (Hymenoptera, Formicidae) as natural control agents of pests in irrigated maize in Nicaragua. Journal of Economic Entomology, 84, 65-70. 
338 Perfecto, I. \& Castineiras, A. 1998. Deployment of the predaceous ants and their conservation in

339

340

341

342

343

344

345

346

347

348

349

350

351

352

353

354

355

356

357

358

359

agroecosystems. In Barbosa, P. (ed.), pp 269-289. Perspectives on the Conservation of Natural Enemies of Pest Species. Academic Press, San Diego, CA.

Perfecto, I. \& Vandermeer, J. 1996. Microclimatic changes and the indirect loss of ant diversity in a tropical agroecosystem. Oecologia, 108, 577-582.

Perfecto, I. \& Vandermeer, J. 2006. The effect of an ant-hemipteran mutualism on the coffee berry borer (Hypothenemus hampei) in southern Mexico. Agriculture, Ecosystems \& Environment, 117, 218-221.

Philpott, S. M. \& Armbrecht, I. 2006. Biodiversity in tropical agroforests and the ecological role of ants and ant diversity in predatory function. Ecological Entomology, 31, 369-377.

Philpott, S. M., Perfecto, I. \& Vandermeer, J. 2008. Effects of predatory ants on lower trophic levels across a gradient of coffee management complexity. Journal of Animal Ecology, $77,505-511$.

R Development Core Team 2016. R: A language and Environment for Statistical Computing. Vienna, Austria.

Ribas, C. R., Schoereder, J. H., Pic, M. \& Soares, S. M. 2003. Tree heterogeneity, resource availability, and larger scale processes regulating arboreal ant species richness. Austral Ecology, 28, 305-314.

Shannon, C. 1948. A mathematical theory of communication. The Bell System Technical Journal, 27, 379-423.

Snelling, R. R. 2007. A review of the arboreal afrotropical ant genus Axinidris. Memoirs of the American Entomological Institute (Gainesville), 80, 551-579. 
360 Stevens, M. M., Madge, D. G., James, D. G., Diffey, S. \& Schiller, L. J. 2007. Ground cover

361

362

363

364

365

366

367

368

369

370

371

372

373

374

375

376 management does not influence densities of key Iridomyrmex species (Hym., Formicidae) in Australian citrus groves. Journal of Applied Entomology, 131(8), 532-536.

Tadu, Z., Djiéto-Lordon, C., Yede, Youbi, E., Aléné, C., Fomena, A. \& Babin, R. 2014. Ant mosaics in cocoa agroforestry systems of Southern Cameroon: influence of shade on the occurrence and spatial distribution of dominant ants. Agroforestry Systems, 88, 10671079.

Vasconcelos, H. L., Leite, M. F., Vilhena, J. M. S., Lima, A. P. \& Magnusson, W. E. 2008. Ant diversity in an Amazonian savanna: Relationship with vegetation structure, disturbance by fire, and dominant ants. Austral Ecology, 33, 221-231.

Way, M. J. \& Khoo, K. C. 1992. Role of ants in pest-management. Annual Review of Entomology, 37, 479-503.

Yee, T. W. 2010. The VGAM Package for Categorical Data Analysis. Journal of Statistical Software, 32, 1-34.

Zuur, A. F., Ieno, E. N., Saveliev, A. A. \& Smith, G. M. 2009. Mixed effects models and extensions in ecology with $R$, New York, Springer-Verlag. 


\section{Table 1 (on next page)}

Occurrence of dominant, subdominant, and subordinate ants at baits. 


\begin{tabular}{|c|c|c|c|c|c|c|}
\hline \multirow[b]{2}{*}{ Species } & \multicolumn{2}{|c|}{ Baits recorded (\%) } & \multicolumn{2}{|c|}{ Baits controlled (\%) } & \multicolumn{2}{|c|}{ Mean abundance score } \\
\hline & $\begin{array}{l}\text { Rainy } \\
\text { season }\end{array}$ & $\begin{array}{c}\text { Dry } \\
\text { season }\end{array}$ & $\begin{array}{l}\text { Rainy } \\
\text { season }\end{array}$ & $\begin{array}{c}\text { Dry } \\
\text { season }\end{array}$ & $\begin{array}{l}\text { Rainy } \\
\text { season }\end{array}$ & $\begin{array}{c}\text { Dry } \\
\text { season }\end{array}$ \\
\hline \multicolumn{7}{|l|}{ Dominant } \\
\hline Pheidole spp. & 36.8 & 43.6 & 25.6 & 37.2 & 3.4 & 3.8 \\
\hline \multicolumn{7}{|l|}{ Subdominant } \\
\hline Axinidris murielae & 0.0 & 10.4 & - & 13.5 & - & 4.2 \\
\hline \multicolumn{7}{|l|}{ Subordinate } \\
\hline Paratrechina longicornis & 32.6 & 36.8 & 11.0 & 9.2 & 2.8 & 2.8 \\
\hline Tetramorium sp. & 11.2 & 13.4 & 7.1 & 20.1 & 2.4 & 3.2 \\
\hline Monomorium bicolor & 16.0 & 7.8 & 12.5 & 15.4 & 2.7 & 2.5 \\
\hline Monomorium sp. 1 & 25.6 & 28.2 & 4.7 & 3.5 & 2.4 & 2.1 \\
\hline Monomorium sp. 2 & 0.0 & 1.2 & - & 0.0 & - & 2.5 \\
\hline Camponotus acvapimensis & 30.2 & 29.8 & 1.3 & 5.4 & 2.3 & 2.2 \\
\hline Camponotus brutus & 22.2 & 15.2 & 9.9 & 7.9 & 2.5 & 2.3 \\
\hline Camponotus sp. 1 & 0.0 & 1.2 & - & 33.3 & - & 3.3 \\
\hline Camponotus sp. 2 & 0.0 & 0.6 & - & 0.0 & - & 3.7 \\
\hline Odontomachus troglodytes & 6.2 & 5.6 & 0.0 & 3.6 & 1.5 & 1.7 \\
\hline
\end{tabular}

1

2 
Table 2 (on next page)

Cultivated plant species in each stratum of diversified plantain-based agroecosystems.

Stratum refers to the location of the plant canopy relative to the soil surface. 


\begin{tabular}{ll}
\hline Stratum & Cultivated plant species \\
\hline Low & Arachis hypogaea L. (groundnut), Xanthosoma sagittifolium (Schott) \\
& (macabo), Colocasia esculenta L. (taro), Dioscorea spp. (yam), Capsicum \\
& anuum L. (hot pepper), Solanum macrocarpon L. (garden egg), Corchorus \\
& spp. (crin-crin), Ananas comosus L. (pineapple), Amaranthus spp., Solanum \\
& lycopersicum L. (tomato), Abelmoschus esculentus (Medik) (gombo), Vigna \\
& $\begin{array}{l}\text { unguiculata L. (cowpea), Ipomoea batatas L. (sweet potato), Zea mays L. } \\
\text { (maize) }\end{array}$ \\
\hline Intermediate & Carica papaya L. (papaya), Manihot esculenta (Crantz) (cassava), Vernonia \\
& spp., Gnetum africanum (eru), Triumphetta pentadra (Rich.) \\
\hline High & Elais guineensis (Jacq.) (oil palm), Coffea Arabica L. (coffee), Theobroma \\
& cacao L. (cocoa), Cola acuminata (Schotte \& Endl.) (cola), Dacryodes edulis \\
& Lam (safou), Persea americana (Mill.) (avocado), Psidium guajava L. (guava), \\
& Mangifera indica L. (mango) \\
\hline Musa & Musa AAA (banana), Musa AAB (plantain) \\
\hline
\end{tabular}

1 


\section{Table 3(on next page)}

Likelihood ratio tests for the strata multinomial model.

Stratum refers to the location of the plant canopy relative to the soil surface. Intermediate, high, and low strata indicate a high density of plants with canopies at intermediate, high, and low strata, respectively. 


\begin{tabular}{lccc}
\hline Variable & $\mathbf{\Delta}$ d.f. & $\mathbf{C h i}^{\mathbf{2}}$ & p-value \\
\hline Intercepts & 5 & 333.29 & $<\mathbf{0 . 0 0 0 1}$ \\
Plant diversity & 5 & 7.68 & 0.174 \\
Intermediate stratum & 5 & 33.14 & $<\mathbf{0 . 0 0 0 1}$ \\
High stratum & 5 & 18.85 & $\mathbf{0 . 0 0 2}$ \\
Musa stratum & 5 & 10.00 & 0.075 \\
Low stratum & 5 & 9.96 & 0.076 \\
\hline
\end{tabular}

1 
Figure 1

Frequencies of numerical dominance of subplots for each ant taxon in the rainy and dry seasons.
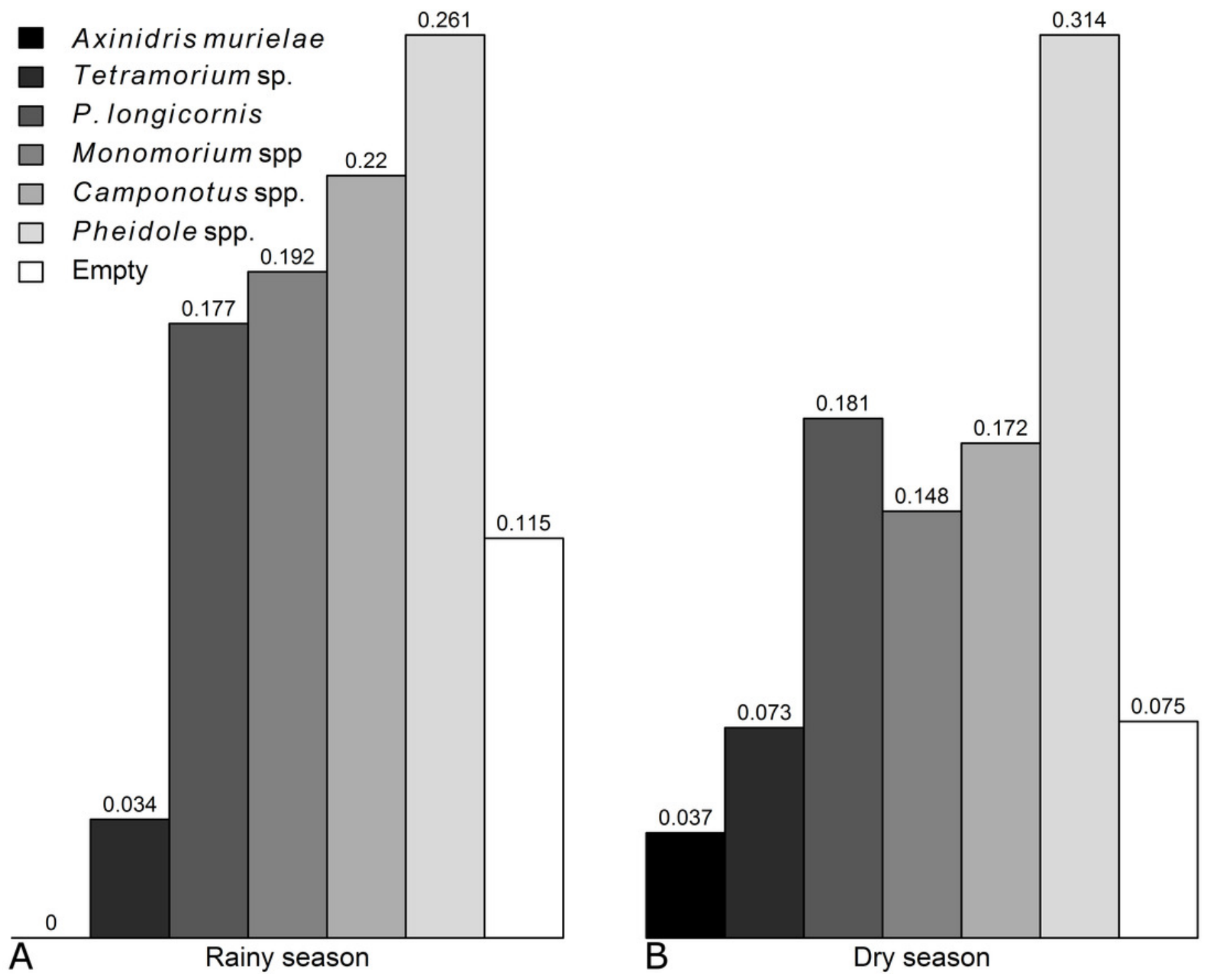
Figure 2

Predicted probability of dominance for each ant taxon.

Grey curves: response to plant density of intermediate stratum; Black curves: response to plant density of high stratum.

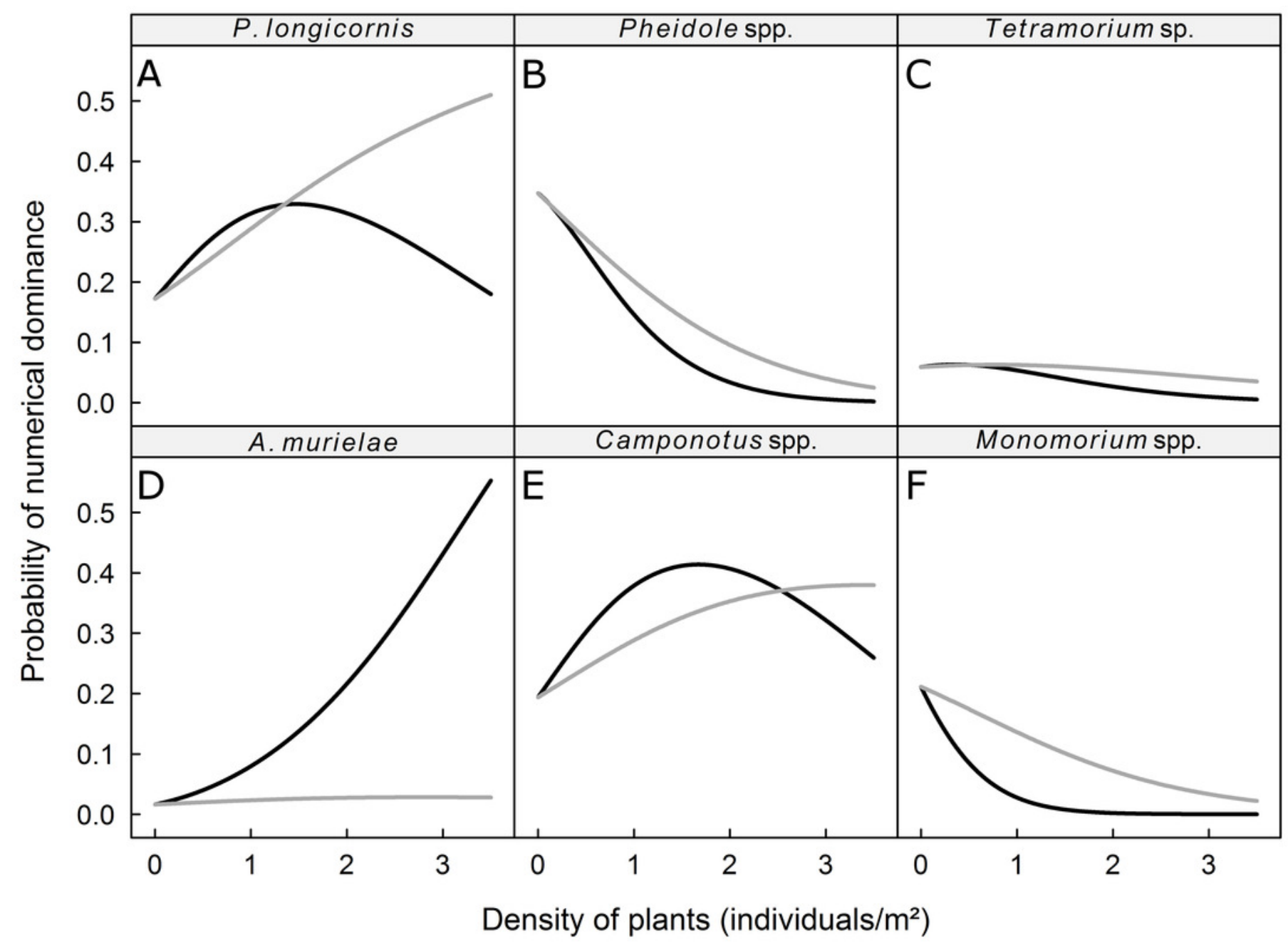

